\title{
Librarians, Self-Censorship, and Information Technologies
}

\section{John Buschman}

This article explores the theme of self-censorship in the library field and its relation to the new technological resources that are becoming very prominent in the profession. A brief discussion of the concept and meaning of censorship and self-censorship is followed by an examination of three broad areas: the results of investing in high-status and high-cost electronic resources; the effect of information technologies on literacy and historical records; and the relationship of electronic resources to market censorship. The author finds that, in each of these three areas, librarians may be self-censoring by not examining the negative effects of movements toward electronic library resources.

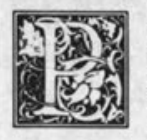

erhaps it may seem curious for librarians to write about issues of censorship and technology. After all, our professional wisdom tells us that information technology is expanding our access to ever more information. Further, the meaning of the word censor is "to examine and expurgate," from the Latin meaning "to assess, estimate, judge." 1 In other words, censorship is commonly something done to others. Selfcensorship is a kind of contradiction, and probably needs some clarification before its relationship to technology is discussed.

Sue Curry Jansen broadens our conception of censorship when she identifies censorship as encompassing those "socially constructed proscriptions and prescriptions which inhibit or prohibit dissemination of ideas ... and other messages ... by political, economic, religious, or other systems of authority."
Self-censorship can be thought of as not assessing, estimating, or judging some of the dimensions of our professional library decisions-our socially constructed proscriptions and prescriptions-thereby leaving assumptions unexamined and some results unchecked for the public we serve. Perhaps Celeste West summed up librarians' selfcensorship most succinctly: "Some things are more equal than others in our minds. We often use lack of funds as a cop-out for exclusion." ${ }^{3}$ It is the purpose of this article to show that this is exactly what is taking place when librarians discuss, decide, and debate information technologies in libraries and their benefits for users. The focus will be on three widely overlooked areas of consequence or possible consequence of information technology in libraries: high-status resources, print literacy and social memory, and market censorship.

John Buschman is Associate Professor-Librarian at Rider College, Lawrenceville, New Jersey 08648. This is a revised version of a paper given as part of a panel with Mark Rosenzweig and Charles Willett on "Self-Censorship in U.S. College and Research Libraries" at the sixth ACRL Conference in Salt Lake City on April 14, 1992. A brief summary of the panel papers was published in Academic Libraries: Achieving Excellence in Higher Education. Proceedings of the Sixth National Conference of the Association of College and Research Libraries, edited by Thomas Kirk (Chicago: ACRL, 1992, 405-407). 


\section{THE COST AND CONSEQUENCES OF HIGH-STATUS RESOURCES}

Early in the twentieth century, scholars of the Frankfurt School began an examination of the hierarchy of social values placed on differing methods of knowing. Western culture, they argued, has elevated scientific rationality as a "preferred value" and as a source of truth and information. As David Held states, the result is that "whatever cannot be reduced to numbers is illusion or metaphysics" or mere humanistic ideology. ${ }^{4}$ Certain kinds of knowledge (scientific, measurable, profitable) have a social prestige and more weight as true knowledge. The implication is, of course, that other forms of inquiry and their resulting knowledge are devalued, regardless of their insight or truth. Critical educational scholars have extended this analysis to the culture of schooling: there are corresponding high- and low-status areas in the curriculum (math/science versus humanities and the softer social studies). ${ }^{5}$

This notion is applicable to our profession: librarians are opting for high-status electronic resources and access at the expense of lower-status (traditional) formats and resources. Information technology, as John Durham Peters states, is the classic product of scientific rationality and the scientific/military establishment. "Information is the stuff of science, and science is (rightly) where [it] has taken

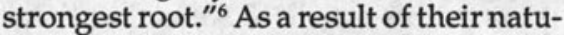
ral affiliation with scientific rationality, information technologies hold a very high status in our culture. It is the socially and economically preferred medium for access to information and soon, to the full text of documents.

The author has written elsewhere that the library profession is adopting information technologies in an unreflective and uncritical way as a means of associating ourselves with the prestige of science and technology, thereby raising our traditional lowly professional social status. ${ }^{8}$ There is no question that libraries of all kinds are spending proportionally more of their budgets on electronic resources, as a recent Library Journal sur- vey pointed out. 9 As a result, our choices of collection building are deeply affected. In 1988 John Haar pointed out, "In many cases, the real choices may be whether to buy ease of bibliographic access at the expense of constricting the acquisition of new monographs and serials..." He further noted that, like the print equivalents they replace, electronic reference resources become the de facto benchmarks for collection building. Since most CD-ROM products are periodical indexes, "underindexed" monographs "may be consequently underutilized." Further, "if selectors respond . . . in conventional fashion, by subscribing to more [periodicals], they will probably do so by reducing budgets for monographic collections." 10 Note that these decisions are not necessarily being driven by the quality of the resources or their value in building a collection, but rather by the need to adjust to electronic information resources. There is evidence, in academic libraries at least, that this is exactly what is happening. "This will further increase the "selectivity," identified by Charles Willett, which discriminates against unestablished or controversial materials. ${ }^{12}$ It is worth noting also that all of this investment in electronic library resources is taking place in an era of stagnant budgets.

There are a few illustrative juxtapositions of the kinds of choices and decisions being made, and clues as to the social and economic values embedded in the choices being made for library users:

- Academic libraries face collection decimation caused by inflation and the lack of budgets to collect and preserve serial and monograph collections while at the same time heavily subsidizing new fee-based research services (which are usually not profitable) for area companies. ${ }^{13}$

- The New York Public Library only recently has found the funds to restore staff and extend hours cut from branch libraries around the city (of primary benefit to local neighborhoods and schoolchildren). In the 
meantime, NYPL was able to proceed with a Science, Industry, and Business Library with an integrated technology system at a cost of $\$ 18.5$ million to the public. ${ }^{14}$

- Finally, former President Bush, in reacting to the recommendations of the WHCLIS, supported "a national network for information sharing . .. copyright statutes and business information centers" but left out endorsing the Omnibus Children and Youth Literacy Initiative-a priority recommendation from the conference. ${ }^{15}$

It is not at all difficult to conclude that information policy leaders and librarians are engaging in a form of self-censorship by not examining the long-term consequences of our purchases of information technologies. There is an unquestioning adoption of the prestige and intellectual bias of the technologies, and this is apparent when one examines the big and small picture of funding and the intellectual and programmatic emphasis in librarianship. The tradeoffs of what we are not purchasing for our users as a result of these investments is self-censored out of our professional discussions.

\section{A LESSENED RELATIONSHIP TO PRINT LITERACY AND SOCIAL MEMORY}

Paul Gherman, in an article in the Chronicle of Higher Education, spelled out in budgetary terms just how the move toward access and electronic text will be accomplished at his university library: "New electronic services and products are high on our list of priorities, on demand information comes next, sustaining important periodicals next, and monographs get the remainder of our budget. The bottom line is that we will be spending more of our budgets for access to information and less on ownership." He goes on to discuss how purchasing access will save the space and physical handling costs printed materials require. In turn he expects that money to be plowed into more access. Eventually, monographs will be printed on demand. To be fair to Gherman, he does not oversell this vision nor under- estimate the nature of the change. However, he does tend to present this as the de facto future of libraries. ${ }^{16}$

This article does not address the question of how the materials to be produced and disseminated electronically are to be chosen for inclusion in the new digital context. That is and will continue to be a process of political and economic selection and there is a danger in creating a new - electronic-canon based on elements of the old canon and highly profitable information. Further, unquestionably the government, business, and the technical establishment are pushing in this direction. A large number of prestigious universities, corporations, professional associations, government agencies, and the leaders affiliated with all of them are sponsoring products, projects, and research in this area. ${ }^{17}$ However, it is questionable whether as a profession we have given any real reflective thought or inquiry to the public consequences to print literacy, the historical record, and social memory.

Bluntly put, electronic text is not just printed text in a different format. There are deeper meanings to electronic text. C. A. Bowers said it most concisely when he noted that "patterns of communication ... mediate the individual's sensory relationship with the environment and re-encode the vocabularies of the culture while at the same time influencing what gets saved and what gets lost in the transmission process." ${ }^{18}$ In other words, there are agendas and forms of power inherent in the structures of communication we are adopting. What follows are some examples of what we are self-censoring (and potentially censoring for our users) by not examining the new mediation and re-encoding of our vocabularies.

John Durham Peters notes that text in an electronic form takes on a different character: it becomes information, "an extraordinarily crumbly, granular, and short-lived stuff. The resistances of [printed] texts to interpretation, and their power to engender many and conflicting readings, evaporates when they become information." 19 If this seems farfetched, consider that a supporter of the 
Dartmouth Dante Project- 600 years of Dante commentary with the full text of Dante's work-described that new environment as a "textual chainsaw" to hack pathways through information that formerly was classic text. ${ }^{20}$ This may or may not be intellectually fruitful or good, but certainly the timeless is becoming timely and may well be obsolete in the next moment. Our professional discussions of such developments and their effects on library users have been absurdly one-sided.

Other kinds of electronic texts - texts with pictures, music, and movement certainly do not fulfill the same learning functions as books. For example, the joint Center for the Advancement of Applied Ethics/Center for Design of Educational Computing project at Carnegie Mellon University seeks to "add the dimension of emotion to ethics education" by bringing in high-quality videodisk pictures to text on an ethical dilemma. They show a burn victim who suffered burns over 65 percent of his body who pleaded with doctors to allow him to die. His therapy, and aspects of his subsequent life-dialing a phone with his tongue-are all shown. ${ }^{21}$ A subtle change has taken place here. Just as television news and issues are now presented and public opinion is formulated, how the burn victim looks and sounds will inevitably be a factor in the ethical decisions reached by the students as a result of their "reading" of the case.

These kinds of resources become a medium to capture attention. Their purpose, as Jay Rosen writes, is to "strike a responsive chord .... The way you communicate is not to send messages (or compose texts). Instead, you fashion a 'package of stimuli' that will resonate with what is already and continuously communicated." 22 Electronic text and multimedia texts result in profound differences with what we know and value about print culture. It is not enough for the profession for librarians to merely say that the changes are coming anyway, so they have no choice but to join in to keep their jobs. We have a social and intellectual responsibility to the public to examine our mission-and not re- define it willy-nilly for convenienceand look deeply at information tech-nologies. Our current trajectory of rhetoric, visions, and plans for the future holds enormous possibilities for self-censoring print literacy from our services to people.

Eugene Provenzo has called the phenomenon of the shift to electronic text and media "post typographic culture," and he has reassessed his original celebration of it. He notes that the integrity of the historical record may become entirely alterable without noticeable traces of change. This is a very real possibility in digital culture, and Provenzo among others sounds a caution: "Anyone who has used a word-processing system with a substitution or replacement function knows how easy it is to transform information in a digital context. One word [or a date] can be automatically substituted for another ... without any record of what the original source said."23

Provenzo also notes that the ability to encode photographs digitally represents another danger to the historical record and social memory. This "represents a major problem in terms of the integrity of historical documents, and the extent to which we can trust the information from such sources in the future." Provenzo concludes that our "ability to alter the past has always been potentially possible [but until now] it has tended ... to be enormously time-consuming and relatively easy to detect." 24 Again, John Durham Peters states that "information lacks history: it belongs only to the present moment and risks being made obsolete in the next." 25

The historical record and social memory are traditional areas that the public has relied upon librarianship to protect. Perhaps they are becoming much more ethereal and manipulable because libraries may no longer be storehouses and archives of records, but rather sites of access in this new vision. There are sufficient technologies available now to control the distribution of text and information electronically. But that system of electronic distribution means that information and text truly can be centrally controlled in terms of access and cost. 
Digital culture, the culture librarians are adopting, nullifies many of the practical brakes on censorship and monitoring of access. Are we giving away values of individual and private patron inquiry?

The technical framework necessary to purchase access on a national scale becomes a reality with library support, but self-censorship prevents us from examining carefully what we may be endangering in the process: privacy and intellectual freedom. Are we still serving the values and strengths of print literacy with this technological trajectory, or unwittingly laying the groundwork of what many scholars have called the electronic panopticon? That would be a society of widespread electronic surveillance and data collection, effectively ending personal and intellectual privacy as we know it. ${ }^{26}$ We are endorsing a new medium which will change the nature of learning, reading, scholarship, and even rationality, as Neil Postman has suggested. ${ }^{27}$ This is not just a new format. In time it will tend to supplant, suppress, and change important social and intellectual values.

\section{INFORMATION TECHNOLOGY AND MARKET CENSORSHIP}

Market censorship has been with us for a long time. Melville complained that "Dollars damn me ... What I feel most moved to write, that is banned, it will not pay." 28 Sue Curry Jansen has explored our new environment and she called it information capitalism-what sells is what gets produced in the first place. She concurs with Dallas Smythe's argument that "the act of modern censorship is essentially a decision as to what is to be mass produced" and it must now be added, how it is to be distributed. It is proper to regard this as censorship Jansen and Smythe argue, because corporations are legally regarded as persons, and fewer and fewer of those "persons" control the worldwide system of communications and information. ${ }^{29}$ Librarianship has grappled with this issue, but self-censorship may be precluding us from seeing the same forces of market censorship at work with information technologies.
Market censorship of library resources is most visible in the growing centralized corporate control of information resources. Many other scholars have detailed this centralizing of ownership and control into a very few corporate hands: Ben Bagdikian, Herbert Schiller, and Patricia Glass Schuman are just a few. Bagdikian summarized what should be librarianship's concern: until now no one "has commanded as much power [as a few media multinationals do now] to shape the information on which so many people depend to make decisions about everything from whom to vote for to what to eat." 30

Librarians are already vigorously debating the issues of this centralization and their meaning for users: privatization; fees for services/information; access to United States Government information; and unequal access for rich and poor. The author has written elsewhere that, if we look carefully, we would see that information technologies have been the driving force behind making much of that centralization possible. Further, there is a bias in the content of the new library electronic resources: those which have had the potential of economic return (i.e., of service to the related agendas of business and science) developed first, and other subjects (the unprofitable humanities and social sciences) developed only later after the market was saturated. There is still a significant imbalance-weighted toward the scientific and profitable-in the content of electronic resources available to our users. ${ }^{31}$

Finally, there is ample evidence that the electronic resources libraries will (and do) purchase are subject to the same centralization of ownership and control, and thus are subject to the same forces of market censorship exercised in other information media. For instance, the publishing giant Elsevier-a prime mover in the journal inflation many libraries face-is introducing document delivery services as a way to fight journal inflation. ${ }^{32}$ The decision to allow the Regional Bell Operating Companies into the information business is another 
illustrative example. While there are no clear-cut good guys in this battle, the presiding judge noted in his ruling that the RBOCs "have no experience in the content or the substance of information." The warnings of the American Association of Publishers about "competing against the enormous monopoly power of the RBOCs" ring true, and there was a frank and open fear that the telephone companies would use their control of regional telephone service to control competing businesses-a practice with long precedent in the telephone business. ${ }^{33}$

James Govan sees in these new resources the real possibility of turning libraries into "retailing shops" and librarians into mere "shopkeepers" remarketing information services-leaving behind public values of service, intellectual freedom, and equal access. ${ }^{34}$ Herbert Schiller perhaps summarized the issue best when he stated, "To imagine that these [new privatized, centralized, and commercialized electronic] services are the sum total of a librarian's contribution is to acquiesce to the emergence of a society in which social aims have been discarded. It would be a society in which commercial goals are achieved efficiently with electronic technology, but in the process, free access to information as a social commitment goes by the wayside." ${ }^{15}$

There are very good reasons to believe that the digital environment librarians are embracing has the potential to be far more subject to market censorship, control, and monitoring than our current environment. Librarians, by not examining the context and parameters of information technology resources available for our users, and the influence of market censorship, are engaging again in a form of self-censorship. Market centralization and the technologies of distribution play a role in what gets produced for the public in the first place, and how equitable will be the public's access. We do not do justice to our professional and intellectual responsibilities to that public when we do not carefully examine who produces and controls what we buy. To paraphrase Charles Willett, "the manufacture of consent" is not a legiti- mate goal of librarians in building collections or the production, distribution, access, and selection of library electronic resources. ${ }^{36}$

\section{CONCLUSION}

When asked if he opposed technology, Mahatma Gandhi once said, "What I object to is the 'craze' for machinery, not machinery as such." ${ }^{37}$ Electronic information resources can provide powerful and enabling possibilities to librarianship. However, we must become more intellectually responsible and mature when we deal with the issues raised by information technologies. To overlook the problems while remaining dazzled only by their possibilities is to engage in the self censorship of not recognizing what we are-and may be-trading away in our choices of formats. Libraries are not value-neutral institutions embodying the best of our current efforts at "information policy." The historical and sociological work by Wayne Wiegand and Michael Harris clearly demonstrates this. ${ }^{38}$ Libraries are, like school curricula, contested terrain in wider battles for economic, social, and intellectual dominance. It is our professional and intellectual responsibility to our users not to self-censor the other issues-the underside of our library information technologies.

Lastly, librarians need to be challenged to shift our one-sided technological discourse. Too often, we are swayed by the great social credibility and prestige of information technology. To question our profession's technological trajectory or even the purchase of the latest CD-ROM product is to stand in the way of enormous, inevitable, and invincible "progress" and be labelled a Luddite-as it is popularly understood-in our profession. Social critics remind us that technologies and their uses are products of human and social decisions, and the results of their use (good and bad) are both planned and accidental. Michael Walzer states the issue best:

Social criticism is critical interpretation.... It is less the practical offspring of scientific knowledge than the edu- 
cated cousin of common complaint. Social critics are individuals ... speaking in public to other members who join in the speaking and whose speech constitutes a collective reflection upon the conditions of collective life.... We become critics ... by elaborating on existing moralities and telling stories about a society more just than, though never entirely different from, our own. ${ }^{39}$ Librarianship needs more social critics of our new information technologies.

\section{REFERENCES AND NOTES}

1. The American Heritage Dictionary of the English Language, 3d ed. (Boston: Houghton, 1992).

2. Sue Curry Jansen, Censorship: The Knot That Binds Power and Knowledge (New York: Oxford Univ. Pr., 1988) 221.

3. Celeste West, "The Secret Garden of Censorship: Ourselves," Library Journal (Sept. 1, 1983): 1651.

4. For an introduction to the history and thought of the Frankfurt School, see David Held, Introduction to Critical Theory (Berkeley, Calif.: Univ. of California Pr., 1980). For shorter treatments of some of the arguments used here, see Jürgen Habermas, "Theory and Practice in a Scientific Civilization," in Paul Connerton, (ed.), Critical Sociology: Selected Readings, (New York: Penguin, 1976); and Henry T. Blanke, "The Mass Culture Debate: Left Perspectives," Progressive Librarian 6/7 (Winter/Spring 1993): 30-51.

5. See Stanley Aronowitz and Henry Giroux, Education under Siege (South Hadley, Mass.: Bergin \& Garvey, 1985); and Michael Carbone, "Empowering the Liberal Arts: Analysis and Paradigms from Critical Theory," Quarterly Journal of Ideology 12 (1988): 4-5.

6. John Durham Peters, "Information: Notes toward a Critical History," Journal of Communication Inquiry 12 (1988): 19-20.

7. For a full exploration of this theme, see chapters by the author in John Buschman, ed., Critical Approaches to Information Technology in Librarianship: Foundations and Applications (Westport, Conn.: Greenwood, 1993).

8. See John Buschman, "Asking the Right Questions about Information Technology," American Libraries (Dec. 1990): 1026-30 and John Buschman, "A Critique of the Information Broker: Contexts of Reference Services," Reference Librarian 31 (1990): 131-51.

9. John Berry, "CD-ROM: The Medium of the Moment," Library Journal (Feb. 1, 1992): 45.

10. John Haar, "The Reference Collection Development Decision: Will New Information Technologies Influence Libraries' Collecting Patterns?" Reference Librarian 22 (1988): 118.

11. See, for instance, May M. Moore, "Compact Disk Indexing and Its Effects on Activities in an Academic Library," Journal of Academic Librarianship 16 (Nov. 1990): 291-95; and Paul Gherman, "Setting Budgets for Libraries in Electronic Era," Chronicle of Higher Education (Aug. 14, 1991): A36.

12. Charles Willett, "Politically Controversial Monographs," Progressive Librarian 4 (1991/92): 28-36.

13. See, for instance, Julie L. Nicklin, "Rising Costs and Dwindling Budgets Force Libraries to Make Damaging Cuts in Collections and Services," Chronicle of Higher Education, (Feb. 19, 1992): A1, A28; Liz McMillen, "Recession Pushes Libraries to Cut Back on Acquisitions of Literary Archives," Chronicle of Higher Education, (Feb. 19, 1992): A29-30; Julie L. Nicklin, "Libraries Drop Thousands of Journals as Budgets Shrink and Prices Rise," Chronicle of Higher Education, (Dec. 11, 1991): A29-30; Michael Rogers, "Library Searching Powers Attract Private Firms," Library Journal, (Apr. 1, 1992): 36; and Julie L. Nicklin, "Many Institutions Conduct Research for Companies for a Fee, But Others Assail the Practice," Chronicle of Higher Education, (Feb. 19, 1992): A29.

14. See "NYPL Takes Major Step to Aid Regional Economic Development," Library Hotline, (Dec. 16, 1991): 1; and Richard F. Shepard, "The Libraries, Squeezed by Hard Times, Shut Children Out," New York Times, (July 14, 1991): E20.

15. See Library Hotline, (Mar. 16, 1992): 1; and J. M. Bandelin, "President Bush Comments on Library Issues," American Libraries, (May 1992): 361.

16. Gherman, "Setting Budgets," A36. 
17. For instance, see Nancy Melin Nelson, "Dynix: Baby Bell Ameritech; DataResearch and 'The' Network," Information Today, (May 1992): 47-48; S. Michael Malinconico, "Information's Brave New World," Library Journal, (May 1, 1992): 37-38; Bruce Flanders, "Multimedia Programs to Reach an MTV Generation," American Libraries (Feb. 1992): 135-36; and Nathaniel Lande, "Toward the Electronic Book," Publishers Weekly, (Apr. 20, 1992): 6.

18. C. A. Bowers, The Cultural Dimensions of Educational Computing: Understanding the Non-Neutrality of Technology (New York: Teachers College Pr., 1988), 2.

19. Peters, "Information," 19-20.

20. See Erik Davis, "Cyberlibraries," Lingua Franca (Feb./Mar. 1992): 46-51.

21. Beverly T. Watkins, "Videodisks Add 'Dimension of Emotion' to Ethics Education," Chronicle of Higher Education (Mar. 4, 1992): A22-23; see also Malinconico, "Information's Brave New World," Flanders, "Multimedia Programs," and Lande, "Toward the Electronic Book."

22. Jay Rosen, "Playing the Primary Chords," Harper's Magazine (Mar. 1992): 23.

23. Eugene F. Provenzo, Jr., "The Electronic Panopticon: Censorship, Control, and Indoctrination in a Post-Typographic Culture," in Myron Tuman, ed., Literacy Online (Pittsburgh: Univ. of Pittsburgh Pr., 1992) 74.

24. Ibid., 174, 179.

25. Peters, "Information," 20.

26. See, for example, Provenzo, "Electronic Panopticon," and Kevin Robins and Frank Webster, "Cybernetic Capitalism: Information, Technology, Everyday Life," in Vincent Mosco and Janet Wasko, eds., The Political Economy of Information (Madison, Wis.: Univ. of Wisconsin Pr., 1988), 57-62.

27. Neil Postman, Technopoly (New York: Knopf, 1992).

28. Quoted in Jansen, Censorship, 19.

29. Ibid., $164-65$.

30. Ben Bagdikian, "Lords of the Global Village," Nation (June 12, 1990): 807; see also Patricia Glass Schuman, "Reclaiming Our Technological Future," Library Journal, (Mar. 1, 1990): 35-38; Herbert I. Schiller, Culture Inc. (New York: Oxford Univ. Pr., 1989); and for recent data, Nancy K. Herther, "Mergers," CD-ROM Professional (Nov. 1992): 40-49.

31. For a fuller treatment of these points, see Buschman, "Critique" and John Buschman and Michael Carbone, "A Critical Inquiry into Librarianship: Applications of the 'New Sociology of Education'," Library Quarterly 61 (1991): 15-40. For more recent data, see Paul Nicholls, "United States History on CD-ROM: A Buyer's Guide," CD-ROM Professional (May 1992): 72-74.

32. Nancy Melin Nelson, "Academic Networks: Publishers Consider Opportunities in Library Technology," Information Today (Dec. 1991): 12.

33. Howard Fields, "Judge Reluctantly Lets 'Baby Bells' Offer Information Services," Publishers Weekly (Aug. 9, 1991): 9; and Joseph A. Webb, "Supreme Court Allows RBOCs to Provide Electronic Information," Information Today (Dec. 1991): 9. For an update, see Carol C. Henderson, The Baby Bells Battle: Who Controls the Info Infrastructure?" American Libraries (Oct. 1992): 800-803.

34. James F. Govan, "The Creeping Invisible Hand: Entrepreneurial Librarianship," Library Journal (Jan. 1988): 35-38.

35. Herbert I. Schiller, "Public Information Goes Corporate," Library Journal (Oct. 1, 1991): 45.

36. Charles Willett, "Politically Controversial Monographs."

37. Mahatma Gandhi, All Men Are Brothers (New York: Columbia Univ. Pr., 1958), 126.

38. See, for instance, Wayne A. Wiegand, "The Role of the Library in American History," in Filomena Simora, ed., The Bowker Annual 33d ed. (New York: Bowker, 1988); and Michael Harris, "The Purpose of the American Public Library," Library Journal (Sept. 15, 1973): 2509-14.

39. Michael Walzer, Interpretation and Social Criticism (Cambridge, Mass.: Harvard Univ. Pr., 1987), 3, 35, 65 . 